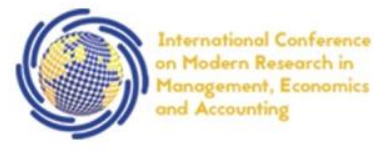

14-16 May, 2021

Paris, France

\title{
The Future of Strategy Implementation Research: Strategy Communication
}

\author{
Jarrah Al-Mansour \\ Assistant Professor, Faculty of Business Administration, AOU Business School, Arab Open University, Kuwait.
}

\begin{abstract}
Although researchers have extensively investigated obstacles to strategy implementation, many public and private organizations continue to face strategy implementation failure. This research examines how strategy is communicated among top and middle managers from a social practice perspective. It argues that strategy implementation research and associated obstacles are no longer representative of strategy failure; rather, it is the accumulation of social interactions among internal social actors that must be understood for strategizing. Our data are based on a single case study of 20 interviews from a public sector organization. The interviewees were in top or middle management roles with decision-making authority. Our results show that internal social actors must align both individual- and group-level cognition prior to the strategy implementation phase. Furthermore, most of the strategy implementation barriers are in fact related to the strategy communication prior to the actual execution of the associated strategic objectives. The findings report a vital concern in terms of how future strategizing should be formed, and thus call for a shift in thought from strategy implementation barriers to the social practice barriers that impede the execution of strategic objectives. This study's exploration contributes to the field by enriching the limited research on strategy communication processes as well as the cognitive understanding of internal social practice.
\end{abstract}

Keywords: strategy process, social practice, strategy divergence, top and middle managers, strategy alignment 